\title{
Vitamin D Status in Pregnant Women of North East India and Impact of Vitamin D Deficiency in Pregnancy on Feto-Maternal Outcome
}

\author{
Dr. Ratna Kanta Talukdar ${ }^{1}$, Dr. Shweta M. Joshi ${ }^{2 *}$ \\ ${ }^{1}$ Professor \& HOD, Department of Obstetrics \& Gynaecology, Gauhati Medical College \& Hospital, Guwahati, Assam, India \\ ${ }^{2}$ Post Graduate Trainee, Department of Obstetrics \& Gynaecology, Gauhati Medical College \& Hospital, Guwahati, Assam, India
}

DOI: $10.36348 /$ SIJOG.2019.v02i12.001

| Received: 30.11.2019 | Accepted: 07.12.2019 | Published: 17.12.2019

*Corresponding author: Dr. Shweta M. Joshi

\section{Abstract}

Background: Despite of sufficient and stable sunny conditions across the equatorial countries, there has been a high prevalence of Vitamin D deficiency (VDD) in pregnancy. The reasons for increased prevalence of VDD are increased time spent indoors, dark skin, and adoption of covered clothing due to religious \& cultural reasons, low socio-economic status that leads to chronically poor diet. The present study was undertaken to find Vitamin D deficiency in the pregnant women of North East India and to find the adverse feto-maternal outcomes associated with VDD. Methods: This prospective study was conducted in the Department of Obstetrics \& Gynaecology, Gauhati Medical College \& Hospital, Guwahati, Assam, and India over a period of one year. Sample size was 150 pregnant women attending antenatal clinic. Results: Out of 150 pregnant women 66 (44\%) had deficient, 41 (27.3\%) had insufficient and $43(28.7 \%)$ had sufficient vitamin D levels. VDD was seen in extremes of age groups i.e. group $\leq 20$ years and 31- 35 years. Multiparity and low socio-economic status was associated with vitamin D deficiency and insufficiency, no association was found between VDD and religion (Hindu \& Muslim). There was significant association between Vitamin D deficiency and insufficiency and occurrence of gestational hypertensive diseases and low birth weight babies. Rate of primary caesarean section was significantly high in vitamin D deficient women. No association was found between VDD and PROM/PPROM, preterm births, gestational diabetes mellitus and neonatal jaundice.

Keywords: Vitamin D deficiency, pregnancy, gestational hypertensive diseases, preterm, gestational diabetes mellitus, LBW.

Copyright @ 2019: This is an open-access article distributed under the terms of the Creative Commons Attribution license which permits unrestricted use, distribution, and reproduction in any medium for non-commercial use (NonCommercial, or CC-BY-NC) provided the original author and source are credited.

\section{INTRODUCTION}

Vitamin $\mathrm{D}$ is produced endogenously following exposure of the skin to ultraviolet radiation with a small proportion derived from exogeneous dietary sources. Despite of sufficient and stable sunny conditions across equatorial countries, studies have reported high prevalence of VDD in pregnant and lactating women in such areas, ranging from $26-95 \%$ during pregnancy [1,2]. Women throughout Asia, Middle East and Africa have been consistently regarded as "high risk" for VDD. Despite of abundant sunshine, VDD has been recognized to be highly prevalent in India.

This paradox is explained by the fact that dark skin pigmentation is at increased risk of VDD. Increased time spent indoors and away from sunlight, liberal sunscreen use, adoption of covered clothing due to religious, cultural or aesthetic reasons and environmental pollution are factors implicated in the increased prevalence of VDD. Women living in low socio-economic strata are unable to meet micronutrient demands of pregnancy due to chronically poor diet. Inadequate access to dietary sources of vitamin D such as fish, dairy products, eggs and having vegetarian diet makes attaining sufficient vitamin D via food sources difficult. Women with one or more of these lifestyle risk factors could be considered vulnerable to VDD.

Pregnancy represents a time period where health status affects two individuals instead of one. With monumental development and growth that occurs in fetus, optimizing health status is imperative. In the pregnant women, it is believed that the primary role of 
vitamin $D$ is immunomodulatory-rather than a calcium-regulating factor, although it would also retain that function. VDD has been associated with increased risk of a number of adverse maternal and fetal health outcomes. These includes an increased risk of gestational hypertensive diseases, gestational diabetes mellitus (GDM), preterm labour, PPROM/PROM, increased incidence of primary caesarean section. For the offspring there is increased risk of low birth weight $(\mathrm{LBW})$, intrauterine growth restriction, neonatal jaundice, and neonatal tetany [3].

\section{METHOD}

This study was conducted in Department of Obstetrics and Gynaecology, Gauhati Medical College \& Hospital, Guwahati over a period of one year after obtaining ethical clearance from the institute.

It was a prospective study. Sample size was 150 pregnant women attending the antenatal OPD of the Department of Obstetrics \& Gynaecology. A written and informed consent was obtained from the subjects.

\section{INCLUSION CRITERIA}

All pregnant women with

- Age :18 to 35 years

- Gestational age less than 24 weeks

- Singleton pregnancy

\section{EXCLUSION CRITERIA}

- Pregnant women with history of medical disorders such as hepatic, renal, metabolic bone disease, malabsorption diseases, thyroid, parathyroid or adrenal and collagen disorders, chronic hypertension, diabetes mellitus

- Previous caesarean section cases

- History of use of drugs interfering with calcium and vitamin $\mathrm{D}$ metabolism like anticonvulsants, corticosteroids etc

Detailed history was recorded including complete demographic details, dietary history, past medical history, previous obstetric history and antenatal history including details of any antenatal complications. All the data was collected in the proforma and it was updated time to time during the follow period.
The pregnant women up to the gestational age of 24 weeks were advised test for determining their Serum Vitamin D levels.

Estimation of 25-hydroxy vitamin D was done by the DIAMETRA 25-OH Vitamin D quantitative solid phase ELISA technique; based on the principle of competitive binding in the Department of Biochemistry, $\mathrm{GMCH}$. A $3 \mathrm{ml}$ venous blood sample is needed for this test.

Diagnosis of gestational diabetes mellitus was made using DIPSI (Diabetes in Pregnancy Study Group India) test. DIPSI recommends $75 \mathrm{mg}$ of oral glucose load and at 2 hours a venous sample is collected for estimating plasma glucose, irrespective of whether she is fasting or non-fasting, without regard to the last meal. GDM is diagnosed if 2 hours plasma glucose is more equal to $140 \mathrm{mg} / \mathrm{dl}$.

PPROM/PROM was diagnosed by a simple per speculum examination for the presence of amniotic fluid coming from Os.

Based on the level of Vitamin D; three groups were determined namely,

A) Vitamin D Deficient group $(\leq 19.9 \mathrm{ng} / \mathrm{ml})$

B) Vitamin D Insufficient group (20-29.9ng/ml)

C) Vitamin D Sufficient group ( $\geq 30 \mathrm{ng} / \mathrm{ml})$

These groups were followed up and studied for the development of

- Maternal complications like gestational hypertension, preeclampsia and eclampsia, PPROM/PROM, gestational diabetes mellitus, preterm labour, mode of delivery.

- Fetal complications like low birth weight, neonatal jaundice.

\section{RESULTS}

Out of 150 pregnant women $66(44 \%)$ had deficient, $41(27.3 \%)$ had insufficient and $43(28.7 \%)$ had sufficient vitamin D levels. The mean vitamin D level of the study population was $24.52 \pm 11.06 \mathrm{ng} / \mathrm{ml}$.

Table-1: Shows the Vitamin D status in pregnancy and mean 25(OH)D levels in the three groups.

\begin{tabular}{|l|l|l|}
\hline Vitamin D status & No. of pregnant women & Mean 25(OH)D levels \\
\hline Deficiency & $66(44 \%)$ & $14.93 \mathrm{ng} / \mathrm{ml}$ \\
\hline Insufficiency & $41(27.3 \%)$ & $24.06 \mathrm{ng} / \mathrm{ml}$ \\
\hline Sufficiency & $43(28.7 \%)$ & $39.66 \mathrm{ng} / \mathrm{ml}$ \\
\hline
\end{tabular}


The mean age of study population was $25.25 \pm 3.72$ years. Vitamin D deficiency was seen more in extremes of age groups $(\leq 20$ years, $47.60 \%)$ and $(31-35$ years group, $36.4 \%)$. Mean level of vitamin $\mathrm{D}$ in the age group 31-35 years was the lowest i.e. $21.99 \mathrm{ng} / \mathrm{ml}$ followed by that of age group 26-30 years i.e. 22.66 $\mathrm{ng} / \mathrm{ml}$. From the mean vitamin D level, it was inferred that the suboptimal level of vitamin D was present in all age groups.54.5\% of the lower socio-economic population had vitamin D deficiency and only $19.5 \%$ had vitamin $\mathrm{D}$ sufficiency. The association between vitamin D status and lower socio-economic status was significant. In this study $50 \%$ pregnant women were primiparous and 50\% multiparous and multiparity was associated with vitamin D deficiency and insufficiency.

Table-2: Shows comparison of the demographic data and parity status with their vitamin D status.

\begin{tabular}{|c|c|c|c|c|}
\hline & $\begin{array}{l}\text { Deficiency } \\
n=66\end{array}$ & $\begin{array}{l}\text { Insufficiency } \\
\mathrm{n}=41\end{array}$ & $\begin{array}{l}\text { Sufficiency } \\
n=43\end{array}$ & $P$ value \\
\hline Age group distribution & \multirow{6}{*}{$\begin{array}{l}10(47.60 \%) \\
23(39 \%) \\
29(49.20 \%) \\
4(36.40 \%)\end{array}$} & \multirow{5}{*}{$\begin{array}{l}6(28.60 \%) \\
14(23.70 \%) \\
16(27.10 \%) \\
5(45.50 \%)\end{array}$} & \multirow{5}{*}{$\begin{array}{l}5(23.80 \%) \\
22(37.30 \%) \\
14(23.70 \%) \\
2(18.20 \%)\end{array}$} & \multirow{5}{*}{0.526} \\
\hline Less than 20 years & & & & \\
\hline $21-25$ years & & & & \\
\hline 26-30 years & & & & \\
\hline $31-35$ years & & & & \\
\hline Religion & & \multirow{3}{*}{$\begin{array}{l}26(28 \%) \\
15(26.30 \%)\end{array}$} & \multirow{3}{*}{$\begin{array}{l}32(34.40 \%) \\
11(19.30 \%)\end{array}$} & \multirow{3}{*}{0.078} \\
\hline Hindu & \multirow{2}{*}{$\begin{array}{l}35(37.60 \%) \\
31(54.40 \%)\end{array}$} & & & \\
\hline Muslim & & & & \\
\hline Socio-economic status & \multirow{4}{*}{$\begin{array}{l}42(54.50 \%) \\
16(34 \%) \\
8(30.80 \%)\end{array}$} & \multirow{4}{*}{$\begin{array}{l}20(26 \%) \\
11(23.40 \%) \\
10(38.50 \%)\end{array}$} & \multirow{4}{*}{$\begin{array}{l}15(19.50 \%) \\
20(42.60 \%) \\
8(30.80 \%)\end{array}$} & \multirow{4}{*}{0.027} \\
\hline Lower & & & & \\
\hline Lower Middle & & & & \\
\hline Middle & & & & \\
\hline Parity & \multirow{3}{*}{$\begin{array}{l}31(41.30 \%) \\
35(46.70 \%)\end{array}$} & \multirow{3}{*}{$\begin{array}{l}19(25.30 \%) \\
22(29.30 \%)\end{array}$} & \multirow{3}{*}{$\begin{array}{l}25(33.30 \%) \\
18(24 \%)\end{array}$} & \multirow{3}{*}{0.044} \\
\hline Primiparous & & & & \\
\hline Multiparous & & & & \\
\hline
\end{tabular}

Out of 43 pregnant women with sufficient vitamin D levels, 32 (74.4\%) women had normal blood pressure with no hypertensive crisis throughout pregnancy, 7 (16.3\%) women developed PIH and only $4(9.3 \%)$ cases developed pre-eclampsia.

Out of 66 vitamin D deficient cases 24 (36.4\%) pregnant women had normal blood pressure, $24(36.4 \%)$ pregnant women developed PIH subsequently during her antenatal course, 15 (22.7\%) cases developed pre-eclampsia and $3(4.5 \%)$ cases landed up having eclampsia.

Out of 41 pregnant women who had vitamin D insufficiency,10 (24.4\%) pregnant women developed $\mathrm{PIH}$, only $4(9.8 \%)$ pregnant women developed preeclampsia. There was significant association between vitamin D deficiency and development of gestational hypertensive disorders. (p value=0.006). The association between vitamin D status and occurrence of preterm labour and rupture of membranes, gestational diabetes mellitus and neonatal jaundice was insignificant.

Out of 66 vitamin D deficient pregnant women, $30(45.5 \%)$ pregnant women delivered by LSCS. In vitamin D insufficient group,12(29.3\%) cases delivered by LSCS, whereas in pregnant women with sufficient vitamin D levels only 11(25.6\%) delivered by LSCS ( $p$ value 0.046). Higher incidence of LSCS occurred in vitamin D deficient group.

$45.5 \%$ born to vitamin D deficient and $39 \%$ born to vitamin D insufficient women had LBW. Vitamin D deficiency and insufficiency was associated with LBW babies. 
Ratna Kanta Talukdar \& Shweta M. Joshi; Sch Int J Obstet Gynec, Dec. 2019; 2(12): 298-303

Table-3: Shows the comparison between feto-maternal outcomes with the vitamin $D$ status.

\begin{tabular}{|c|c|c|c|c|}
\hline & $\begin{array}{l}\text { Deficiency } \\
\mathrm{n}=66\end{array}$ & $\begin{array}{l}\text { Insufficiency } \\
\mathrm{n}=41\end{array}$ & $\begin{array}{l}\text { Sufficiency } \\
n=43\end{array}$ & $\mathrm{P}$ value \\
\hline Gestational hypertensive diseases & \multirow{3}{*}{$\begin{array}{l}24(36.40 \%) \\
24(36.40 \%) \\
15(22.70 \%) \\
3(4.50 \%)\end{array}$} & \multirow[b]{2}{*}{$\begin{array}{l}26(63.40 \%) \\
10(24.40 \%) \\
4(9.80 \%) \\
1(2.40 \%)\end{array}$} & \multirow[b]{2}{*}{$\begin{array}{l}32(74.40 \%) \\
7(16.30 \%) \\
4(9.30 \%) \\
0(0.00 \%)\end{array}$} & \multirow[b]{2}{*}{0.006} \\
\hline $\begin{array}{l}\text { Normotensive } \\
\text { PIH } \\
\text { Pre-eclampsia } \\
\text { Eclampsia }\end{array}$ & & & & \\
\hline Gestational age at delivery & & \multirow{3}{*}{$\begin{array}{l}32(78.00 \%) \\
9(22.00 \%)\end{array}$} & \multirow{3}{*}{$\begin{array}{l}37(86.00 \%) \\
6(14.00 \%)\end{array}$} & \multirow{3}{*}{0.5} \\
\hline $\begin{array}{l}\text { Term }(\geq 37 \text { weeks }) \\
\text { Preterm }(<37 \text { weeks })\end{array}$ & \multirow[t]{2}{*}{$\begin{array}{l}51(77.30 \%) \\
15(22.70 \%)\end{array}$} & & & \\
\hline PPROM/PROM & & & & \\
\hline $\begin{array}{l}\text { Absent } \\
\text { Present }\end{array}$ & \multirow[t]{2}{*}{$\begin{array}{l}52(78.80 \%) \\
14(21.20 \%)\end{array}$} & \multirow[t]{2}{*}{$\begin{array}{l}33(80.50 \%) \\
8(19.50 \%)\end{array}$} & \multirow[t]{2}{*}{$\begin{array}{l}38(88.40 \%) \\
5(11.60 \%)\end{array}$} & 0.426 \\
\hline Mode of delivery & & & & \\
\hline $\begin{array}{l}\text { Vaginal } \\
\text { Cesarean } \\
\text { Instrumental }\end{array}$ & \multirow{3}{*}{$\begin{array}{l}32(48.50 \%) \\
30(45.50 \%) \\
4(6.10 \%) \\
60(90.90 \%) \\
6(9.10 \%)\end{array}$} & $\begin{array}{l}29(70.70 \%) \\
12(29.30 \%) \\
0(0.00 \%)\end{array}$ & $\begin{array}{l}31(72.10 \%) \\
11(25.60 \%) \\
1(2.30 \%)\end{array}$ & 0.046 \\
\hline Gestational diabetes mellitus & & & & \\
\hline $\begin{array}{l}\text { Non-GDM } \\
\text { GDM }\end{array}$ & & $\begin{array}{l}38(92.70 \%) \\
3(7.30 \%)\end{array}$ & $40(93 \%)$ & 0.908 \\
\hline Birth weight & \multirow{3}{*}{$\begin{array}{l}30(54.5 \%) \\
66(45.5 \%)\end{array}$} & & & \multirow[b]{2}{*}{0.032} \\
\hline $\begin{array}{l}\text { Normal birth weight }(\geq 2.5 \mathrm{~kg}) \\
\text { Low birth weight }(\leq 2.4 \mathrm{~kg})\end{array}$ & & \multirow[t]{2}{*}{$\begin{array}{l}25(61.00 \%) \\
16(39.00 \%)\end{array}$} & \multirow[t]{2}{*}{$\begin{array}{l}34(79.00 \%) \\
9(21.00 \%)\end{array}$} & \\
\hline Neonatal jaundice & & & & \\
\hline $\begin{array}{l}\text { Absent } \\
\text { Present }\end{array}$ & $\begin{array}{l}51(77.50 \%) \\
15(22.70 \%)\end{array}$ & $\begin{array}{l}33(80.50 \%) \\
8(19.50 \%)\end{array}$ & $\begin{array}{l}35(81.40 \%) \\
8(18.60 \%)\end{array}$ & 0.854 \\
\hline
\end{tabular}

\section{DISCUSSION}

In this study the vitamin $\mathrm{D}$ deficiency, insufficiency \& sufficiency was found $44 \%, 27.3 \%$, $28.7 \%$ of subjects respectively.

Sharma et al. at NEIGRIHMS, Meghalaya (India); found that vitamin D deficiency was present in $84.18 \%$ of pregnant women and vitamin D insufficiency in $12.44 \%$ [4]. Pahuja et al. at Himalayan Institute of Medical Science, Uttarakand (India) found that $21 \%$ pregnant women were vitamin D deficient \& $69 \%$ were vitamin D insufficient [5].

This study had $47.6 \%$ and $28.6 \%$ of pregnant women in $\leq 20$ years age-group with vitamin D deficiency \& insufficiency respectively. In advanced age-groups i.e. $26-30$ years, $49.2 \%$ and $27.1 \%$ women had vitamin D deficiency \& insufficiency. In age-group 31-35 years vitamin D deficiency \& insufficiency was seen in $36.4 \%$ and $45.5 \%$. From this study it was concluded that vitamin D deficiency \& insufficiency was present in extremes of age groups. Al Shaik et al. had similar finding in their study done in Saudi Arabia. They found that $52 \%$ of vitamin D deficient and $53.1 \%$ vitamin $\mathrm{D}$ insufficient women belong to ages between 25 to 35 years [6].
Amongst Muslim population, $54.4 \%$ were vitamin D deficient \& $19.3 \%$ had sufficient levels of vitamin D. amongst Hindu, $37.6 \%$ were vitamin D deficient and $34.4 \%$ vitamin D sufficient. There was no statistical significance between the vitamin D status of Hindu and Muslim pregnant women. Similarly, Alok Sachan et al. in their study on vitamin D deficiency among pregnant women in northern India found no difference between the vitamin D status of Hindu and Muslim population [7].

This study showed significantly poor vitamin D status in pregnant women belonging to lower socioeconomic class. $54.5 \%$ of pregnant women of lower socioeconomic strata had vitamin $\mathrm{D}$ deficiency. However, Nimitphong and Holick M. in their study on vitamin D status in South Asia found that vitamin D deficiency is prevalent equally in lower and upper class [8].

Vitamin D deficiency was more in multiparous women as compared to primiparous in this study. Alshaikh et al. in their study also found that $66.8 \%$ of vitamin D deficient and $75.5 \%$ of vitamin D insufficient women were multiparous [6]. 
Vitamin D is thought to play a significant role in preeclampsia as an immune modulator. It helps by mounting an appropriate maternal immune response to the placenta preventing the release of anti-angiogenic factors into the bloodstream and modulating hypertension.

In the present $36.4 \%$ of vitamin $\mathrm{D}$ deficient pregnant women suffered from PIH, $22.7 \%$ developed pre-eclampsia, $4.5 \%$ ended up having eclampsia. $24.4 \%$ of vitamin D insufficient pregnant women suffered from PIH, 9.8\% developed preeclampsia, $2.4 \%$ ended up having eclampsia. Bodnar et al. USA in a case control study found positive correlation between vitamin D deficiency and development of preeclampsia [9].

Worldwide studies claim that vitamin D participates in immunological processes that prevent bacterial invasion, which may indirectly influence duration of pregnancy. Cytokines released by maternal and fetal systems in response to bacterial invasion leads to production of prostaglandins which then triggers preterm contractions. However, many studies have failed to prove this association.

In this study, $22.7 \%$ of vitamin D deficient women had preterm labour and $77.3 \%$ had it at term and $22 \%$ of vitamin D insufficient women had preterm labour and $78 \%$ had it at term. Similarly, Lixia Yang et $a l$. in their prospective study conducted in China to find the correlation between vitamin D deficiency and preterm birth found no evidence of an increase in preterm birth in relation with vitamin D deficiency [10].

In this study, $21.2 \%$ of vitamin D deficient pregnancies had ROM and in vitamin D insufficient group $19.5 \%$ of pregnant women had ROM and $11.6 \%$ of vitamin D sufficient pregnant women had ROM. This study could not prove significant association between poor vitamin D as causal for rupture of membranes. Similarly, in a prospective observational study conducted in Southern China by J. Zhou et al. it was found that $20.81 \%$ of vitamin D deficient, $22.73 \%$ of vitamin D insufficient and $21.04 \%$ of vitamin D sufficient pregnant women had prelabour rupture of membranes [11].

The vitamin D receptor has been identified throughout the body, including the uterine smooth muscle and skeletal muscle. Vitamin D deficiency is associated with poor muscle performance in humans leading to increase in caesarean section. Many studies conducted worldwide have successfully proven that poor vitamin $\mathrm{D}$ status increases the rate of primary caesarean section.

In this study, $45.5 \%$ of vitamin D deficient pregnancies landed up having caesarean section while $48.5 \%$ had vaginal delivery and $6.1 \%$ had instrumental delivery, in vitamin D insufficient group $29.3 \%$ had caesarean delivery. In this study, vitamin D deficiency had significant association with increase in the rate of primary caesarean section. In a large prospective study conducted at Boston by Anne Merewood et al. it was found that there exists an inverse association between caesarean section and serum $25(\mathrm{OH}) \mathrm{D}$ levels. In their study $28 \%$ pregnant women with vitamin $\mathrm{D}$ deficiency had caesarean section when compared to $14 \%$ pregnant women with sufficient vitamin $\mathrm{D}$ levels to have caesarean delivery [12].

There are several evidences supporting the role of vitamin $\mathrm{D}$ in maintaining glucose homeostasis and the fact that VDD can lead to glucose intolerance. But very few clinical studies conducted worldwide have proven this association.

In this study, $8 \%$ of the pregnant women were diagnosed with gestational diabetes mellitus. In vitamin D deficiency group $9.1 \%$ pregnant women developed GDM, $7.3 \%$ of vitamin D insufficient pregnant women developed GDM, whereas $7 \%$ of pregnant women with sufficient vitamin D levels developed had GDM. There was no association between poor vitamin D status in pregnancy and occurrence of GDM in this study. A case control study was conducted by Baker et al in USA, wherein they found those 5 individuals with vitamin D deficiency in 60 GDM cases and 8 individuals with vitamin $\mathrm{D}$ deficiency in 120 controls. The $\mathrm{p}$ value was 0.90 making this association insignificant [13]. Helena $\mathrm{H}$ et al in their study found no difference in pregnancy 25(OH)D concentration between GDM and non-GDM women (82 vs $82 \mathrm{nmol} / \mathrm{L}, \mathrm{P}=0.99$ ) [14].

In this study, $45.5 \%$ of vitamin D deficient and $39 \%$ of vitamin D insufficient pregnant women delivered babies weighing less than or equal to $2.4 \mathrm{~kg}$ (LBW) whereas only $21 \%$ of vitamin D sufficient pregnant women delivered LBW babies. So, there was a significant association between vitamin D deficiency in pregnancy and low birth weight babies in this study.

Similarly, Wang et al. from their study concluded that maternal vitamin D insufficiency during pregnancy is independently associated with low birth weight and have a high risk of SGA in term fetus [15]. Sharma $\mathrm{N}$ et al. in their study found that the maternal mean vitamin D level in low birth weight group was $12.17 \mathrm{ng} / \mathrm{ml}$ which was significantly low in comparison with the normal birth weight group where it was 17.45 $\mathrm{ng} / \mathrm{ml}[4]$.

The metabolisms of bilirubin and vitamin D happen in two separate paths, but they may affect each other since one stage of their synthesis takes place in liver. So far, few studies have examined the relationship between neonatal hyperbilirubinemia and maternal serum vitamin D. 
In one case control study conducted in Iran by Shahrokh Mehrpisheh et al. it was found that there was no correlationship between neonatal jaundice and maternal and neonatal vitamin D deficiency [16]. In the present study, there was no significant association between developments of neonatal jaundice in babies born to vitamin D deficient mothers.

\section{CONCLUSION}

This study showed that the prevalence of VDD in pregnancy is astonishingly high and there was significant association between hypovitaminosis D and occurrence of gestational hypertensive diseases and low birth weight babies. Rate of primary caesarean section was significantly high in vitamin D deficient women. The paucity of clinical studies on the extent of vitamin $\mathrm{D}$ deficiency in pregnancy and adverse impact of it on maternal and fetal health and also the high cost of vitamin $\mathrm{D}$ estimation makes the universal antenatal screening and even the highrisk screening of pregnant women for vitamin D an economically challenging task. Despite a dearth of interventional evidence supporting supplementation/treatment of vitamin D in randomised controlled trial settings, it is generally accepted that supplementation/treatment is not harmful and may have some significant short and long term health benefits. Treatment of vitamin D deficient women and prophylactic vitamin D supplementation is safe and is recommended for all women who are pregnant or breastfeeding. Encouragement for moderate outdoor activity for adequate exposure to sunlight is desirable.

\section{REFERENCES}

1. Alfaham, M., Woodhead, S., Pask, G. (1995). Vitamin D Deficiency: A Concern in Pregnant Women. Br J Nutr, 73:881-887.

2. Mulligan, M.L., Felton, S.K., Riek, A.E., BernalMizrachi, C. (2010). Implications of vitamin D deficiency in pregnancy and lactation. Am J Obstet Gynecol, 202:429. e1-9.

3. Hollis, B.W., Pittard, W.B. (1984). Evaluation of the Total Fetomaternal Vitamin D Realation at Term. J Clin Endocrinol Metab, 59:652-657.

4. Sharma, N., Nath, C., Mohammad, J. (2019). Vitamin D status in pregnant women visiting a tertiary care center of North Eastern India. J Family Med Prim Care, 8:356-60.
5. Pahuja, N., Chauhan, N., Kalra, V. (2018). Vitamin D levels in pregnant women in Uttarakhand, India. Int J Reprod Contracept Obstet Gynecol, 7:169-72.

6. Al-Shaikh, G., Ibrahim, G., Fayed, A. (2016). Impact of vitamin D deficiency on maternal and birth outcomes in the Saudi population: a crosssectional study. BMC Pregnancy and Childbirth, 16:119.

7. Sachan, A., Gupta, R., Das, V. (2005). High prevalence of vitamin D deficiency among pregnant women and their newborns in northern India. Is J Clin Nutr, 81:1060-4.

8. Nimitphong, H., Michael, H. (2013). Vitamin D status and sun exposure in Southeast Asia, Dermato-Endocrinology, 5:1, 34-37.

9. Bodnar, L., Janet, M. (2007). Maternal Vitamin D Deficiency Increases the Risk of Preeclampsia. J Clin Endocrinol Metab, 92: 3517-3522.

10. Yang, L., Pan, S., Zhou, Y. (2016). The Correlation between Serum Vitamin D Deficiency and Preterm Birth. Med Sci Monit, 22: 4401-4405.

11. Zhou, J., Su, L., Liu, M. (2014). Associations between 25-hydroxyvitamin D levels and pregnancy outcomes: a prospective observational study in southern China. European Journal of Clinical Nutrition. 2014; 68:925-930.

12. Merewood, A., Mehta, S., Chen, T. (2009). Association between Vitamin D Deficiency and Primary Cesarean Section. J Clin Endocrinol Metab, 94: 940-945.

13. Baker, A., Haeri, S., Carlos, A. (2012). Firsttrimester maternal vitamin D status and risk for gestational diabetes (GDM) a nested case-control study. Diabetes Metab Res Rev, 28(2): 164-168

14. Hauta-alus. (2017). Maternal vitamin D status, gestational diabetes and infant birth size. BMC Pregnancy and Childbirth, 17:420.

15. Wang, H., Xiao, H., Zhang, Y. (2018). Maternal early pregnancy vitamin D status in relation to low birth weight and small for gestational age offspring. The Journal of Steroid Biochemistry and Molecular Biology, 175,146-150.

16. Mehrpiseh, S., Memarian, A., Mahyar, A. (2018). Correlation between Serum Vitamin D Level and Neonatal Indirect Hyperbilirubinemia. BMC Pediatrics, 18:178. 